\title{
Prescribing skills for undergraduate medical students: Time to redress the
}

\section{neglect?}

Shankar PR ${ }^{1}$

${ }^{1}$ Professor, Xavier University School of Medicine, Aruba, Kingdom of the Netherlands

Chief Editor

Dr. Indrajit Banerjee

Technical Editor

Dr. Nishida Chandrasekharan

Formatting Editor

Dr. Indrajit Banerjee

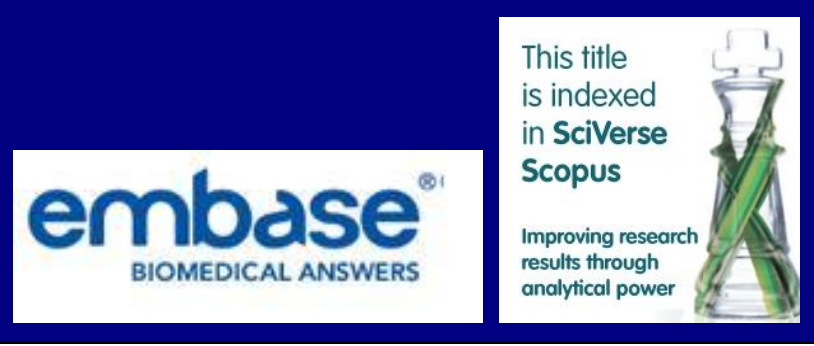

\section{Editorial}

\section{Corresponding Author:}

Dr. P Ravi Shankar MD

Xavier University School of Medicine

Aruba, Kingdom of the Netherlands

E-mail: ravi.dr.shankar@gmail.com

Medical schools have a major challenge of preparing undergraduate students to choose and prescribe safe and cost-effective treatments. Problem-based learning in pharmacology based on national essential medicine lists and standard treatment guidelines has been recommended as a key intervention to improve prescribing ${ }^{1}$. Recognizing the fact that traditional pharmacology teaching concentrates on memorizing information about medicines a number of initiatives have been introduced to improve teaching-learning of rational therapeutics.

Recognizing the vital importance of the subject, the World Health Organization (WHO) has developed four publications dealing with teaching rational use of medicines (RUM). These are 'Guide to good prescribing' (http://whqlibdoc.who.int/hq/1994/who_dap_94.11.pdf), 'Ethical criteria for medicinal drug promotion' (http://apps.who.int/medicinedocs/documents/whozip08e/ whozip08e.pdf), 'How to investigate drug use in health facilities' http://apps.who.int/medicinedocs/en/d/Js2289e/) and a book for teachers titled 'Teacher's guide to good prescribing'(http://apps.who.int/medicinedocs/en/m/abstr
act/Js2292e/). 'Guide to good prescribing' was used to conduct rational pharmacotherapy training for fourth year medical students in a medical school in Turkey ${ }^{2}$. Case-based teaching was used to impart rational pharmacotherapy skills to students in India ${ }^{3}$ and developing and using a personal formulary was found to be effective in schools following both a traditional and a problem-based curriculum ${ }^{4}$.

In a medical school in Lalitpur, Nepal students learn about various aspects of RUM during small group pharmacology learning sessions ${ }^{5}$. Personal (P) drug selection using objective criteria and unbiased sources of medicine information is an important exercise in pharmacology. At present in Nepal the exercise is being conducted at Manipal College of Medical Sciences, Institute of Medicine and KIST Medical College ${ }^{6}$. The P-drug selection process uses a logical deductive process, using accurate and objective information, to adopt strict criteria (efficacy, safety, convenience and cost, on selecting drugs and writing a complete prescription ${ }^{7}$. In a medical school in Brazil students liked the methodology and the opportunity to reflect on various factors involved in the prescribing process but could not use it much in practice due to lack of stimulation and not being allowed to do so by older residents and senior doctors ${ }^{7}$.

In the United Kingdom initiatives to improve prescribing have recently been carried out ${ }^{8}$. Prescribe, a repository of elearning materials to support education in clinical pharmacology and prescribing has been created, and the Prescribing Skills Assessment, a national online assessment designed to allow medical students to 
demonstrate that they have achieved the core competencies required to begin postgraduate training has been developed. The author recommends greater visibility of clinical pharmacology and therapeutics in the curriculum, clear learning outcomes that are consistent with national guidelines, strong and enthusiastic leadership, a student formulary, opportunities to practice prescribing, a robust assessment of prescribing competencies and external quality control to improve prescribing and reduce errors.

A recent article had mentioned ten basic competencies for undergraduate education in pharmacology ${ }^{9}$. Among these was familiarity with the national essential medicines list, ability to carry out the P-drug selection process, awareness of pharmaceutical promotion and the ability to respond to the same, knowledge of independent objective sources of medicine information, ability to use antibiotics rationally, analyzing prescribing using drug use indicators, counseling patients regarding use of medicines, reporting adverse drug reactions to a pharmacovigilance center and performing pharmaceutical calculations.

Challenges in teaching health science students about rational use of medicines include reservations of faculty members about the new learning resources, unfamiliarity with small group teaching, lack of involvement of pharmacologists in teaching therapeutics during the clinical years of training and non-involvement of pharmacists and pharmacologists in patient care activities ${ }^{10}$. These challenges have to be overcome and a major reorientation and refocusing of pharmacology departments in medical schools towards rational therapeutics may be needed. Modern medical education I feel focuses heavily on diagnosis of disease conditions. Considering the increasing complexity of modern treatment regimens, cost of care and the different stakeholders involved it is time 'prescribing skills' receive the attention and resources it richly deserves!

\section{References}

1. Laing RO, Hogerzeil HV, Ross-Degnan D. Ten recommendations to improve use of medicines in developing countries. Health Policy Plan 2001;16:13-20.

2. Gelal A, Gumustekin M, Arici MA, Gidener S. Rational pharmacotherapy training for fourth-year medical students. Indian J Pharmacol 2013;45:4-8.

3. Kamat SK, Marathe PA, Patel TC, Shetty YC, Rege NN. Introduction of case based teaching to impart rational pharmacotherapy skills in undergraduate medical students. Indian J Pharmacol 2012;44:634-8.

4. De Vries TP, Daniels JM, Mulder CW, Groot OA, Wewerinke L, Barnes KI, Bakathir HA, Hassan NA, Van Bortel L, Kriska M, Santoso B, Sanz EJ, Thomas M, Ziganshina LE, Bezemer PD, Van Kan C, Richir MC,Hogerzeil HV. Should medical students learn to develop a personal formulary? An international, multicentre, randomised controlled study. Eur J Clin Pharmacol 2008;64:641-6.

5. Shankar PR, Jha N, Bajracharya O, Shrestha R,
Thapa HS. Teaching Pharmacology at a Nepalese Medical School: The Student Perspective. Australas Med J 2010;1:14-22.

6. Banerjee I. Concepts of P-drug selection. Nepal Journal of Epidemiology 2013;3:226-9.

7. Patrício KP, Alves NA, Arenales NG, Queluz TT. Teaching the Rational Use of Medicines to medical students: a qualitative research. BMC Med Educ 2012;12:56.

8. Maxwell SR. How should teaching of undergraduates in clinical pharmacology and therapeutics be delivered and assessed? $\mathrm{Br} J$ Clin Pharmacol 2012;73:893-9.

9. Shankar PR. Ten basic competencies for undergraduate pharmacology education at KIST Medical College, Lalitpur, Nepal. Australas Med J 2011;4:677-82.

10. Shankar PR. Teaching health science students about rational use of medicines - time to take up the gauntlet. The Journal of Medicine Use in Developing Countries 2009;1(3):1-2.

\section{Article Information}

\section{Article history}

Received

$29^{\text {th }}$ August 2013

Received in revised form

$3^{\text {rd }}$ September 2013

Accepted

$23^{\text {rd }}$ September 2013 